\title{
Effectiveness of a Group Counseling Program in Transcendental Meditation in Improving the Level of General Psychological Adjustment for Grade Eleven Female Students in Muscat Governorate Muna Abdul Majeed Al Lawati
}

Educational Researcher, Master of Education in Psychological Counseling, Muscat, Sultanate of Oman
Abstract
The study aimed to build a group counseling program in transcendental meditation (TM) and evaluate its effectiveness in enhancing the level of general psychological adjustment of female students in the eleventh grade in the governorate of Muscat, Sultanate of Oman, using a semi-empirical method. In order to select the sample of the study, the researcher used the general psychological adjustment scale on eleventh grade female students in the Omamabint Abi Al Aas School for basic education in the governorate of Muscat. Out of 76 female students, 30 students, who attained the lowest grades in the scale, were chosen for the study. The sample was randomly divided into two groups: an experimental group of 15 students who were trained in the group counseling program in TM, prepared by the researcher, and a control group of 15 students who did not receive any training in the program. The group counseling program included 12 counseling sessions over six weeks (two sessions a week). Each session was 45-60 minutes long. They also received a pre-program, a post-program, and a follow-up session. The program was based on the theory of cognitive behavioral therapy (CBT) and focused on cognitive behavioral methods. The results of the study were as follows:
1. Statistically significant differences $(\alpha \leq 0.05)$ were found in the scales of psychological adjustment, for the total scale and for each of its dimensions, between the individuals of the two groups: the experimental and the control. The post-test scores were more favorable in the experimental group, which indicates the effectiveness of the group counseling program used in this study.
2. Statistically significant differences $(\alpha \leq 0.05)$ were found between the pre-test and post-test results in the psychological adjustment totals of the scale and for each of its dimensions. These differences were more favorable in the post-test, where the $\mathrm{P}$ value in all of it was less than (0.05), which indicates the effectiveness of the group counseling program used in this study.
3. No statistically significant differences of $(\alpha \leq 0.05)$ were found between the post-test and the follow- up for the psychological adjustment total scale and for each of its dimensions for the experimental group, where P was greater than (0.05), which indicates that the effect of the group counseling program continues.
Based on these results, the study made several recommendations and suggestions to achieve improvement in the level of general psychological adjustment for students of various age groups.

\section{Introduction}

Meditation is an ideal method for reaching a deep understanding ofwhat is around us - for reachinga state of awareness. Researchers suggest that meditation is necessary for psychological and emotional well-being. It is also the basis of many cognitive processes. It should not be ignored or neglected in the education system. It is essential for educators to develop the skills of meditation because it is an important mode of thinking.

Post-primary students are considered to be among groups that are most likely to be vulnerable to stress, mental distraction andinability to pay attention, concentrate and engage, under achievement and maladjustment, because this phase is the phase when ambtions and aspirations are achieved and decisions about the future are made. This adolescent phase weakens young people's ability to deal with stressful events. This results in difficulty in adjusting and the inability to use their previous experiences to solve current problems [1].

Several studies have been undertaken to consider the positive effects of practicing TM. The first of these studies were published at the beginning of the 1970s. They concluded that practicing this

\section{Publication History:}

Received: October 05, 2017

Accepted: December 25, 2017

Published: December 27, 2017

\section{Keywords:}

Group Counseling Program, Transcendental Meditation, General Psychological Adjustment technique resulted in a state of rest and alertness. The following studies examined the role of TMin reducing rates of hypertension, obesity, depression and other physical diseases. Although they found some positive correlation, it is worth mentioning that these results are not definitive [2].

\section{Problem of the study}

Many parents and educators recognize that adolescence is associated with many negative connotations. Adolescence is described as a difficult phase, an overwhelming phase, a rebellion phase, and a phase

"Corresponding Author: Muna Abdul Majeed Al Lawati, Educational Researcher, Master of Education in Psychological Counseling, Muscat, Sultanate of Oman; E-mail: munalawati@yahoo.com

Citation: Al Lawati MAM (2017) Effectiveness of a Group Counseling Program in Transcendental Meditation in Improving the Level of General Psychological Adjustment for Grade Eleven Female Students in Muscat Governorate. Int J Psychol Behav Anal 2: 135. doi: https://doi.org/10.15344/2017/2455-3867/135

Copyright: @ 2017 Al Lawati. This is an open-access article distributed under the terms of the Creative Commons Attribution License, which permits unrestricted use, distribution, and reproduction in any medium, provided the original author and source are credited. 
Citation: Al Lawati MAM (2017) Effectiveness of a Group Counseling Program in Transcendental Meditation in Improving the Level of General Psychological Adjustment for Grade Eleven Female Students in Muscat Governorate. Int J Psychol Behav Anal 2: 135. doi: https://doi.org/10.15344/2017/2455-3867/135

Page 2 of 6

of successive crises. In the twentieth century, many studies of teenagers were undertaken. Most of these early studies concentrated only on the biological and psychological factors. Then other studies emerged that the stressed problems in adolescence were the result of the interaction between biological and social factors. Internal changes alongside social expectations create for the teenager moments of hesitation, selfskepticism and disappointment [3].

Despite the great efforts exerted by educators in schools, there are some students who undergo a decrease in their level of psychological adjustment. This may happen because they do not have efficient skills that enable them to deal with the challenges and difficulties they face.

Thus, the present study attempts to answer the following question: Is it possible to improve the level of general psychological adjustment among eleventh grade female students by using the TM program?

\section{Objectives of the study}

This study aims to develop a group counseling program in TM,toassess its efficiency in improving the level of general psychological adjustment among a sample of grade eleven female students in Muscat Governorate, and, if there are benefits from the TM technique, to suggest alternative preventive and therapeutic services for female students.

\section{Significance of the study}

The importance of this study stems from the fact that, too often,most people live a life of tension and worry and a low level of psychological and physiological health because of psychological pressures, many of which they are unaware of, but whichthey face every day. The study is also important because of the importance of the educational phase it deals with. This phase is in urgent need of such counseling programs and, in particular, preventive programs, in order to achieve appropriate psychological adjustment among students. Moreover, the study is important because of the positive results and benefits shown by this kind of treatment,which has become an important ingredient of modern healthcare. It is , indeed, essential because of the scarcity of Arabic research, studies and counseling programs of this nature.

\section{Hypotheses of the study}

The study aims to investigate the following hypotheses:

1. There are no statistically significant differences at the level of significance $(\alpha \leq 0.05)$ between the members of the empirical and control groups on the general psychological adjustment scale and on every one of its dimensions in the post measurement attributed to the group counseling program.

2. There are no statistically significant differences at the level of significance $(\alpha \leq 0.05)$ between the pre-measurment and postmeasurment on the general psychological adjustment scale and on every one of its dimensions for the empirical group.

3. There are no statistically significant differences at the level of significance $(\alpha \leq 0.05)$ between the post-measurement and the follow-up measurement for members of the empirical group on the general psychological adjustment scale and on every one of its dimensions.

\section{Terminology of the study}

Transcendental Meditation: is defined in this study as an easy-tolearn technique that the individual can practice by comfortably sitting on a chair or on the floor, with eyes closed for 15-20 minutes twice a day.

Psychological Adjustment: is defined as the ability to face pressures and challenges positively in order to bring about a change in behavior, according to environmental circumstances, and to reach a state of comfort, happiness, self-satisfaction and satisfaction with others, in accordance with the degree obtained by members of the sample on the general psychological adjustment scale used in this study.

Post-primary education: is defined as "a two-year system of schooling after primary education that spans ten school years. The system aims to continuously develop basic skills, job skills and career planning among students to ready them to become active members in society and able to benefit from education opportunities [4]."

Group Counseling Program: is defined as a group counseling program developed by the researcher. It involves a group of clear and specific scientific steps and meauresin the field of psychological couseling. It covers counseling methods and skills and is based on the theories of psychological counseling. It offers a set of information, experiences and activities for eleventh grade female students with the aim of improving their health and achieving psychological adjustment.

\section{Determiners of the study}

\section{The findings of the study are determined by:}

1. A sample of eleventh grade female students at Omamabint Abi Al Aas school in Muscat Governorate for the school year $2014 / 2015$

2. The two tools of the study, which are represented by the psychological adjustment scale and the group counseling program in TM developed by the researcher to be applied to the sample and to verify their psychometric characteristics.

3. The range of validity of answers given by the sample and the psychometric characteristics of the two tools of the study.

\section{The relation between transcendental meditation and psychological adjustment}

1. Many studies conducted on the possible effects of TM indicate that there is a positive relation between TMand many physiological and psychological variables such as worry, creativity, mental performance, level of energy, innovation, selfconfidence and endurance [5]. These variables contribute to the individual's psychological health and adjustment.

2. Moreover, TMcan have profound effects on the deep structure of the character. Various studies have found that practicing TM techniques promotes a level of psychological health and improvesa focus on positive values [7].

3. The meditator can reach a stage at which he or she can spread the positive effects and benefits of meditation that appear in his behavior and demonstration of emotions. S/he can transfer them to others, especially in the family setting. S/he can create a comfortable environment and achieve a level of familial and social psychological adjustment [8]. 
Citation: Al Lawati MAM (2017) Effectiveness of a Group Counseling Program in Transcendental Meditation in Improving the Level of General Psychological Adjustment for Grade Eleven Female Students in Muscat Governorate. Int J Psychol Behav Anal 2: 135. doi: https://doi.org/10.15344/2017/2455-3867/135

Page 3 of 6

\section{Review of related literature}

Frew [8] refers to three studies that relate to this research. They explore the relationship between TM and work productivity.

- Blasdale's study on motion performance and its relation to TM found that TMhas a positive effect on mental and physical adjustment, physical flexibility, and sensory attention and neurological-muscular integration. He concludes that those who practice TM are faster and more accurate in terms of motor activities.

- Abram's study of the relationship between TM and learning abilities concludes that those who practice TM learn faster and more accurately. He also finds an increase in the positive relationship the longer the duration of meditation. Those who have experience in meditation are faster and more accurate than those who have not.

- $\quad$ Siman, Nedish and Banta's study uses the personality orientations detecting tool in order to study the individual's self-achievement level. It concludes that those who practice meditation have more self-realization as a result of meditation.

\section{Review of related literature}

Frew [8] refers to three studies that relate to this research. They explore the relationship between TM and work productivity.

Hanley and Spates [9] conducted a study in TM and sociopsychological attitudes that aimed to compare the findings of seven variables for 23 students who practicedTM in the students' dormitories of four universities and colleges in the USA with the findings of other students from the same universities, by using a questionnaire designed to analyse six socio-psychological orientations. The meditating students show more positive results in five of the six orientations.

Chandler's study, entitled Transcendental Meditation and Awakening Wisdom, aimed to measure the range of effectiveness of TM in enhancing the growth of wisdom in graduates of Maharishi International University in the USA. Thirty-four graduates took part in the study. An analysis was carried out on three variables: selfdevelopment, confidence and moral thinking. The variables provide an insight into the growth of wisdom. This includes self-development, effective performance and cognitive development within a moral framework. The study collected data on self-development in three university control groups of students who equal to the Maharishi graduates in gender and age. There is a noticeable growth in selfdevelopment and an increase in the levels of confidence and moral thinking among the graduates of Maharishi University in comparison to the control groups. These findings encourage the study to recommend that it is beneficial for educators to practice TM in order to promote their wisdom.

So and Orme-Johnson's study includes three trials on the longitudinal effects of TM techniques on cognitive perception. The study was conducted on 362 secondary school students from three schools in Taiwan. The study's hypothesis assumed that the regular practice of TM techniques for 15-20 minutes daily for 6-12 months would improve their cognitive perception susceptibility. In all the trials, the same seven variables were used. These are a thinking test, the Test for Creative Thinking Drawing Production (TCT-DP), the Constructive Thinking Inventory (CTI), the Implicit Figures Group
Test (GEFE), the State-Trait Anxiety Inventory (STAI), the Inspection Time (IT), and the Culture Fair Intelligence Test (CFIT). The mono variables test shows that practicing TM results in significant effects on all variables compared to the control group.

Chandler, Alexander and Heaton [10] conducted a longitudinal study over ten years in Washington, entitled The Transcendental Meditation Program and Post Conventional Self-Development. The Ego Development Test, confidence stimulation and moral thinking applied to a sample comprising 136 individuals. Findings showed that individuals who practiced TM showed a noticeable increase in ego development, compared with three control groups that comparable in gender and age in the same period. The findings showed that the sample individuals who practiced TM showed a remarkable increase in the level of moral thinking and confidence. The findings confirm that self-sustaining growth can be gradually achieved through the exercises that are based on TM.

Grosswald et al. [11] conducted a study to examine the effect of using TM techniques to reduce the symptoms of attention deficit hyperactivity disorder (ADHD) by reducing stress and anxiety. The study was conducted for three months in a school in the United States, for children who suffer from ADHD. The empirical sample consisted of 10 students who ranged between 11 and 14 years old. Half of them treated by medication. Students practiced TM for 10 minutes every day in the morning and in the evening. They also underwent many performance tests to measure their cognitive functions. Three months later, therewas a decrease of more than $50 \%$ in psychological stress and anxiety. There was also a noticeable improvement in the symptoms of ADHD. For the children on medication, improvement was either not sufficient or it was accompanied by side effects. These results show that TM may be very beneficial for young people who have ADHD.

Tanner's study [12], entitled The Effect of Transcendental Meditation on Mindfulness, aimed to explorethe relation between TM and mindful awareness. The study was conducted on 295 students from universities located in Washington DC. The Kentucky Inventory of Mindfulness Skills was used in the study. Results show a correlation between time and the treatment period. The TM group scored better in pre-tests and post-tests. These findings indicate that TM increases mindful awareness and that those who have a tendency to practice TM have a greater level of mindful awareness according to the variation of the structure of mindful awareness among meditators.

Elder et al. [13] conducted a study to evaluate the impact of practicing a TM program on psychological stress among student groups who belong to ethnic minorities in America. Results indicated that there was a decline in anxiety and psychological stress among the practice group students compared to the control group students. The positive impact on depressive disorders was also noticed. The study concludes that it is important for principals to implement meditation programs in their schools in order to reduce tension and psychological stress among students.

In a study entitled Academic Achievement and Transcendental Meditation conducted by Nidich et al. [14], the study community comprisedmiddle school students in the United States who were at risk of failure in academic achievement. The sample consisted of 189 students who had low achievement in English and mathematics. The study was conducted to evaluate the range of variation in academic achievement among the students of middle schools who were practicing TM compared to those in control groups. The comparison 
Citation: Al Lawati MAM (2017) Effectiveness of a Group Counseling Program in Transcendental Meditation in Improving the Level of General Psychological Adjustment for Grade Eleven Female Students in Muscat Governorate. Int J Psychol Behav Anal 2: 135. doi: https://doi.org/10.15344/2017/2455-3867/135

Page 4 of 6

was carried out using California Standards Tests (CST). All sample students were from the same school and they completed the curriculum followed there. Ninety seven per cent of them came from ethnic minority groups. The meditating students practiced $\mathrm{TM}$ in the school twice a day as part of an independent program for three months. The findings showed that there was an improvement in attainment in English and mathematics among the students who practiced meditation compared with the control groups. This indicates that practicing meditation regularly in school helps to bridge the gap in achievement among students who are vulnerable to the risk of academic failure by improving the level of their achievement.

Aldahadha [15] looked into the effects of Muslims' prayers and the TM program on mindfulness among students of the University of Nizwa. The sample consisted of 354 students. The Al-kushooa Questionnaire and Kentucky Inventory of Mindfulness Skills were used for pre-tests and post-tests. After three months of training on the TM program of one 30-minute session per week, results showed that Al-Kushooahelps to promote mindful awareness. The results also indicatea positive effect of the TM program in enhancing the level of mindful awareness.

Napora's study [16], entitled The Impact of Classroom-Based Meditation Practice on Cognitive Engagement, Mindfulness and Academic Performance of Undergraduate College Students aimed to explore the role of meditation in the classroom and its effect on cognition, mindful awareness and academic performance in a sample of 189 male and female students in New York. They were aged between 18 and 37 years. They were divided into an empirical group (102 individuals) and a control group (87 individuals). A mindful awareness questionnaire and a cognitive scale were used. The empirical group participated in ameditation program for six minutes a day throughout one full semester and on a continuous basis. The results showed many significant correlations among three variables and in particular between cognition and mindful awareness. The results indicate that mindful awareness has a more important role in the learning process and in the level of academic performance than cognition The evidence from this study supports the use of methods that enhance the level of mindful awareness and work as effective learning tools. This demonstrates the educational efficiency of practicing meditation in classrooms.

In Ramsburg and Youmans' study [17], entitled Meditation in the Higher-Education Classroom: Meditation Training Improves Student Knowledge Retention during Lectures, the effect of meditation on the students' retention of information was tested by applying three experiments. 183 male and female students took part in the experiments. All were students of psychology at California State University,including two graduates. Participants in the three experiments randomly received either a brief training on meditation or they rested. Then they attended a lecture in the classroom. Finally, they participated in a post-lecture test to evaluate the range of their knowledge about the subject of the lecture. The findings in all these experiments showed that meditation improves the students' retention of the information delivered to them in the lecture.

Dwairy [18] conducted a study entitled Parenting and Adolescents' Psychological Adjustment: Toward a Systemic Approach in Parenting Research. The study examined the relation between the factors of family and paternity and teenagers' psychological disorders in accordance with a methodological model that analyses eight family factors and eleven paternity factors as well as two formal factors which are the teenager's gender and culture. The study was based on the data of 1358 male teenagers and 1526 female teenagers from nine countries. Findings indicated that family and paternal factors have a strong correlation with teenagers' psychological disorders. They are implicated in $37.2 \%$ of these disorders.

Al-Atawi [19] conducted a study that aimed to design a cognitive behavioural counseling program in order to enhance the level of psychological social adjustment and reduce the desire to drop out from school among secondary school students in the Tabook region, through applying CBT counseling techniques on the sample by using a semi-empirical method. The sample consisted of 30 students who were randomly chosen. They were divided into two groups: an empirical group (15) and a control group (15). Pre-test, post-test and followup tests were applied. The findings showed statistically significant differences between the average scores of the members of the empirical group and those of the control group in enhancing the level of psychological social adjustment and decreasing the desire to drop out from school in the post-test measurement. The differences were seen in the direction of the empirical group members in psychological social adjustment and in the direction of the control group members in the desire to drop out from school. Significant differences also appeared between the average of the degrees of the empirical group in the post-measurement and the follow-up measurement in enhancing the level of psychological and social adjustment and decreasing the desire to drop out from school. The variations in psychological and social adjustment came in the direction of follow-up measurement and in the direction of the post measurement in decreasing the indications of the desire to drop out from school.

Turnbull and Norris [20] conducted a study at Birmingham University in UK to examine the effect of TMon self-identity indexes and personality. The study was conducted through interviews with 14 participants who completed the Eysenck Personality Questionnaire (EPQ) once before starting to practice the TM program and twice after practicing it. The group was compared to a group that did not learn TM. The two groups were evaluated by the same method and at the same time. At the beginning, the two groups differed only in that the meditation group had a tendency to judge that they were different from their ideal selves. As the study progressed, findings showed a pattern of significant changes over the three tests. The meditation group started to recognize the similarity between their real, ideal and social selves. They developed a healthy self-concept of their real selves. The findings of the Eysenck Personality Questionnaire showed more relaxation among the meditators.

Rosaen and Benn's study was a qualitative study that aimed at exploring the experiences of middle school students who regularly practice TM. The design of the study consisted of qualitative interviews with a sample of 10 students from middle schools in Michigan state, USA, who had practiced TM for one year. Among the useful conclusions of the study are the students' description of the positive effects of practicing TM, such as an increase in the relaxed attention state, the ability to self-mediate and self-control, emotional flexibility and the improvement of academic performance. The attention state that resulted from meditation led to the growth of emotional and social capabilities necessary to regulate emotional fluctuations and psychological stress among adolescents.

Hong et al. [21] conducted a study to explore the effect of a functional group counseling program on stimulating low-achieving students to self-assessment and self-proficiency. The study was conducted on a 
Citation: Al Lawati MAM (2017) Effectiveness of a Group Counseling Program in Transcendental Meditation in Improving the Level of General Psychological Adjustment for Grade Eleven Female Students in Muscat Governorate. Int J Psychol Behav Anal 2: 135. doi: https://doi.org/10.15344/2017/2455-3867/135

Page 5 of 6

sample of tenth grade students in Taiwanese schools. The sample was divided into an empirical group with 34 low achievers and a second sample of 43 middle and high achievers. The students' vocational questionnaire and a group counseling program were used in the study.

Hong et al. [21] conducted a study to explore the effect of a functional group counseling program on stimulating low-achieving students to self-assessment and self-proficiency. The study was conducted on a sample of tenth grade students in Taiwanese schools. The sample was divided into an empirical group with 34 low achievers and a second sample of 43 middle and high achievers. The students vocational questionnaire and a group counseling program were used in the study. In addition, the direct observation of two male and four female lowachieverswas used. Findings showed a noticeable increase in the level of self-evaluation and self-efficiency among the members of the empirical group, compared with the second group. The counseling program had a clear impact on low achievers. The study recommends that it is important to use practical group counseling programs to increase self-evaluation in low achievers.

\section{Methodology and Design of the Study}

This study adopts semi-empirical methodology that consists of one empirical group and one control group in order to determine the effectiveness of a group counseling program in TM in improving the level of general psychological adjustment in the empirical group compared to the control group. Table 1 clarifies the empirical design of the study.

\section{Study population}

The study population consists of all eleventh grade female students at Omamabint Abi Al Aas school in Al-Khoudh for the school year 2014/2015. The number of students according to the official statistics of the Public Directorate of Education in Muscat Governorate is 244. The school was chosen by the simple random method (voting) from among 17 schools in the governorate.

\section{Sample of the study}

The researcher chose by the simple random method 76 eleventh grade female students from the chosen school. She applied the general psychological adjustment scale on them. After correcting the scale, 30 students were selected. These were those with the lowest scores on the scale. Their scores ranged between 17 and 29 . She randomly divided the sample into two groups (empirical and control) of 15 students each, by assigning odd numbers for the empirical group and even numbers for the control group.

\section{Variables of the study}

The study contained two variables; they are as follows:

1. Independent variable: a group counseling program in TM

2. Functional variable: the level of general psychological adjustment.

\section{Tools of the study}

\section{A group counseling program in TM}

The program is based on CBT. It targets 15 female students, representing the empirical group in the study sample of 30 students. The general target of the program is to improve the level of general psychological adjustment among the eleventh grade female students through training them in the TM technique.

\section{Organization of the program:}

- The program consists of four basic phases: the starting phase, the transfer phase, the construction and work phase and the completion phase.

- It consists of twelve counseling sessions as well as a preprogram session (the preliminary session) and a post-program session (follow-up and evaluation session). The time for one session is $45-60$ minutes, according to the procedures followed in every session.

- The period of implementation of the program is six weeks with two sessions weekly, in addition to the opening and closing sessions.

\section{Counseling methods and tools used in the program:}

Since the researcher depended in building this program on cognitive behavioural theory, there is a focus on some cognitive and behavioural methods that meet the individuals' needs and desires. These methods are: dialogue, discussion and persuasion, direct observation, lecture, simulation or modeling, pros and cons checklist, deep breathing, selftalk, refutation, cognitive reconstruction, imagination, meditation drills, wonder technique, household duty, feedback and interaction and communication.

\section{The general psychological adjustment scale}

The researcher used the general psychological adjustment scale [22], which contains forty sections distributed into four dimensions: the first dimension (personal adjustment), the second dimension (social adjustment), the third dimension (family adjustment) and the fourth dimension (emotional adjustment). The answers for the scale sections are two options: yes or no.

In order to make the scale accord with the study, the researcher added three sections to the first dimension and seven sections to the fourth dimension in such a way that the scale now contained 50 sections distributed into the four dimesions as follows:

\begin{tabular}{|l|l|l|}
\hline Dimensions of the scale & Items & Items added to the scale \\
\hline Personal adjustment & $1-12$ & $10,11,12$ \\
\hline Social adjustment & $13-23$ & \\
\hline Familial adjustment & $24-33$ & \\
\hline Emotional adjustment & $34-50$ & $44,45,46,47,48,49,50$ \\
\hline
\end{tabular}

\begin{tabular}{|c|c|c|c|c|c|}
\hline Random Distribution R & Group G & $\begin{array}{c}\text { Pre- measurement } \\
\text { O1 }\end{array}$ & $\begin{array}{c}\text { Applying the counseling } \\
\text { program } \\
\times\end{array}$ & $\begin{array}{c}\text { Post- } \\
\text { measurment } \\
\text { O2 }\end{array}$ & $\begin{array}{c}\text { Follow-up } \\
\text { measurment } \\
\text { O3 }\end{array}$ \\
\hline $\mathrm{R}$ & $\begin{array}{c}\mathrm{G} 1 \\
\text { empirical }\end{array}$ & $\mathrm{O} 1$ & $\times$ & $\mathrm{O} 2$ & $\mathrm{O} 3$ \\
\hline $\mathrm{R}$ & $\begin{array}{c}\mathrm{G} 2 \\
\text { empirical }\end{array}$ & $\mathrm{O} 1$ & No treatment & $\mathrm{O} 2$ & $\mathrm{O} 3$ \\
\hline
\end{tabular}

Table 1: The empirical design of the study.

Int J Psychol Behav Anal

ISSN: 2456-3501

IJPBA, an open access journal Volume 2. 2017. 135 
Citation: Al Lawati MAM (2017) Effectiveness of a Group Counseling Program in Transcendental Meditation in Improving the Level of General Psychological Adjustment for Grade Eleven Female Students in Muscat Governorate. Int J Psychol Behav Anal 2: 135. doi: https://doi.org/10.15344/2017/2455-3867/135

Page 5 of 6

\section{The statistical equality of the two groups}

In order to verify the statistical equality of the empirical and control groups, the averages and standard deviations were calculated for the scores of the participants on the total scale and on each of its dimensions on the pre-measurement. Table 3 shows the results.

\begin{tabular}{|c|c|c|c|c|}
\hline Dimensions & Group & $\mathrm{N}$ & Mean & Standard Deviation \\
\hline Personal Adjustment & Empirical & 15 & 5.40 & 1.12 \\
\hline & Control & 15 & 5.67 & 1.68 \\
\hline Social Adjustment & Empirical & 15 & 7.00 & 1.07 \\
\hline & Control & 15 & 5.87 & 1.92 \\
\hline Familial Adjustment & Empirical & 15 & 6.33 & 2.26 \\
\hline & Control & 15 & 7.13 & 2.23 \\
\hline Emotional & Empirical & 15 & 5.53 & 2.20 \\
Adjustment & Control & 15 & 6.40 & 2.44 \\
\hline Total Degree & Empirical & 15 & 24.27 & 4.38 \\
\hline & Control & 15 & 25.07 & 3.61 \\
\hline
\end{tabular}

Table 3: The averages and standard deviations of the total general psychological adjustment scale each of its dimensions among the particpants in the empirical and control groups in the pre measurement.

It is clear from table 3 that the averages of the general psychological adjustment scale scores for the members of the empirical group measured on the total scale and on each of its dimensions in the premeasurement are close to theaverages of the general psychological adjustment scale scores for the members of the control group measured on the scale and on each of its dimensions.

Due to the small size of the sample, data distribution was tested. It was found that the distribution was non-moderate. Therefore, the significance of these differences was verified by using the nonparametric Mann-Whitney test shown in table 4.

\begin{tabular}{|c|c|c|c|c|c|}
\hline Dimensions & Group & $\mathrm{N}$ & $\begin{array}{c}\text { Total of } \\
\text { classes }\end{array}$ & $\mathrm{Z}$ & $\mathrm{P}$ \\
\hline Personal Adjustment & Empirical & 15 & 217.50 & 646. & 518. \\
\hline & Control & 15 & 247.50 & & \\
\hline Social Adjustment & Empirical & 15 & 277.50 & 1.773 & 076. \\
\hline & Control & 15 & 187.50 & & \\
\hline Familial Adjustment & Empirical & 15 & 209.50 & 971. & 332. \\
\hline & Control & 15 & 255.50 & & \\
\hline Emotional Adjustment & Empirical & 15 & 212.50 & 841. & 400. \\
\hline & Control & 15 & 252.50 & & \\
\hline Total Degree & Empirical & 15 & 227.00 & 396. & 692. \\
\hline & Control & 15 & 238.00 & & \\
\hline
\end{tabular}

Table 4: Mann-Whitney test for the pre-application of the total scale and of each of its dimensions on the empirical and control groups.

It is clear from Table 4 that there are no statistically significant differences at the level of significance (0.05) in the pre-application of the scale between the empirical and control groups. This indicates that the two groups are statistically equal.

\section{Verifying the psychometric characteristics of the scale:}

\section{A: Validity of the scale}

Int J Psychol Behav Anal

ISSN: 2456-3501
In order to acknowledge the validity of the general psychological adjustment scale, the researcher used the following validity types:

\section{Apparent validity (validity of judges)}

The initial formula of the scale was shown to 14 judges from Nizwa University and Sultan QabousUniversity. The judges are experts and specialists in the field of psychological counseling, psychology and measurement and evaluation. An agreement percentage of $80 \%$ among them has been adopted.

\section{Validity of structure}

The researcher chose a sample outside the original sample of the study. That sample included 76 eleventh grade female students. Using the internal harmony method, Pearson Correlation was calculated in order to ascertain the connection between the total of every dimension and the grand total of the scale and the connection between every section and the total of the dimsension to which it belongs. It was found that there was a statistically significant connection between the total of every one of the dimensions and the total of the scale at the level of significance (0.01). The correlation was also calculated between the sections of the scale and the dimension to which they belong. It was found that there was a connection between the sections of the scale and the total of every dimension. Some were at the level of significance (0.05) and others were at the level of significance (0.01). This means that the majority of the sections of the scale had valid structures except six sections that were not statistically significant and which were consequently excluded from the scale. Therefore, the scale included inits final form 44 sections.

\section{B. Stability of the scale}

The researcher used Cronbach's Alpha Correlation in order to ascertain the internal harmony for every one of the scale's dimensions and also for the total scale of the study. It was found that the scale had accepted stability for its four dimensions and also for its total.

\section{Correcting the scale}

The scale contains 23 positivelyoriented secions. They are $1,3,6$, $7,8,12,15,16,18,19,22,23,25,27,29,31,32,34,35,41,42,43,44$. If the examined female student's answer was Yes, she would be given one mark (1). But if the answer was No, she would be given zero (0). The scale also contains 21 negativelyoriented sections. They are 2,4 , $5,9,10,11,13,14,17,20,21,24,26,28,30,33,36,37,38,39,40$. If the examined female student's answer was No, she would be given one mark (1). But if her answer was Yes, she would be given zero (0).

Since every response can be measured from (0) to (1), the minimum total of the scale is (0) and the maximum total is (44).

\section{Statistical processing}

The researcher used the statistical package (SPSS) as well as the following statistical methods:
1) Pearson Correlation
2) Cronbach's Alpha Correlation
3) Mann-Whitney U Test
4) Wilcoxon U Test
5) Spearman Brown Equation 
Citation: Al Lawati MAM (2017) Effectiveness of a Group Counseling Program in Transcendental Meditation in Improving the Level of General Psychological Adjustment for Grade Eleven Female Students in Muscat Governorate. Int J Psychol Behav Anal 2: 135. doi: https://doi.org/10.15344/2017/2455-3867/135

Page 5 of 6

\section{Discussing the findings related to the first hypothesis}

The first hypothesis of the study stated that there were no statistically significant differences at the level of significance $(\alpha \leq 0.05)$ among the members of the empirical and control groups on the general psychological adjustment scale and on eachof its dimesnsions in the post-measurment attributable to the group counseling program.

In order to choose this hypothesis, the averages and standard deviations were calculated for the scores of the members of the empirical and control groups on the total scale and on each of its dimensions in the post measurement as is shown in table 5.

\begin{tabular}{|c|c|c|c|c|}
\hline Dimensions & Group & $\mathrm{N}$ & Mean & Standard Deviation \\
\hline Personal Adjustment & Empirical & 15 & 7.73 & 1.099 \\
\hline & Control & 15 & 5.67 & 1.877 \\
\hline Social Adjustment & Empirical & 15 & 8.67 & 2.093 \\
\hline & Control & 15 & 6.13 & 2.446 \\
\hline Familial Adjustment & Empirical & 15 & 8.33 & 976. \\
\hline & Control & 15 & 6.40 & 1.844 \\
\hline Emotional Adjustment & Empirical & 15 & 10.00 & 2.752 \\
\hline & Control & 15 & 6.93 & 3.081 \\
\hline Total Degree & Empirical & 15 & 34.73 & 5.378 \\
\hline & Control & 15 & 25.40 & 6.092 \\
\hline
\end{tabular}

Table 5: The averages and standard deviations of the total score on the general psychological adjustment scale and on each of its dimensions between the members of the empirical and control groups in the post measurement.

It is clear from table 5 that the averages of the scores of psychological adjustment for the members of the empirical group measured on the total general psychological adjustment scale and on each of its dimensions at the post measurement are greater than the averages of the psychological adjustment for the members of the control group measured on the total scale and on each of its dimensions.

Given the small size of the sample, the data distribution was tested. It was found that the distribution is non-moderate. Therefore, the indications of these differences were verified by using the MannWhitney $\mathrm{U}$ test. Table 6 shows the results of the test.

Table 6 shows that there are statistically significant differences at the level of significance $(\alpha \leq 0.05)$ for the total scale and for each of its dimensions between the members of the empirical and control groups in the post measurement. These differences are infavour of the empirical group in the total scale and in each of its dimensions. The statistical significance ranged between (0.001) and (0.007). All of them are less than (0.05). Thisindicates the effectiveness of the group counseling program used in this study to improve psychological adjustment in the members of the empirical group compared to the members of the control group in the post measurement.

The researcher suggests that these positive findings are due to the program's positive effect on the empirical group of students. This effect contributed to the improvement of their psychological adjustment, controling and regulating their emotions and decreasing tension and stress in this adolescent phase. The program also contributed to the re-orgainzation of their perception of negative thoughts and emotions that they might encounter in stressful situations. It enabled them to develop the concept of self and to adopt positive values.

\begin{tabular}{|c|c|c|c|c|c|}
\hline Dimensions & Group & $\mathrm{N}$ & $\begin{array}{c}\text { Total of } \\
\text { classes }\end{array}$ & $\mathrm{Z}$ & $\mathrm{P}$ \\
\hline Personal Adjustment & Empirical & 15 & 306.00 & 3.102 & 0.002 \\
\hline & Control & 15 & 159.00 & & \\
\hline Social Adjustment & Empirical & 15 & 296.50 & 2.685 & 0.007 \\
\hline & Control & 15 & 168.50 & & \\
\hline Familial Adjustment & Empirical & 15 & 306.50 & 3.131 & 0.002 \\
\hline & Control & 15 & 158.50 & & \\
\hline Emotional Adjustment & Empirical & 15 & 298.50 & 2.754 & 0.006 \\
\hline & Control & 15 & 166.50 & & \\
\hline Total Degree & Empirical & 15 & 315.50 & 4.453 & 0.001 \\
\hline & Control & 15 & 149.50 & & \\
\hline
\end{tabular}

Table 6: The results of the Mann-Whitney Test onthe post measurement on the total scale and on each of its dimensions ofthe empirical and control groups.

The program also developed their mental and cognitive capabilities and strengthened their ability to learn and memorize.

\section{Discussing the findings related to the second hypothesis}

The second hypothesis of the study suggested that there were no statistically significant differences at the level of significance $(\alpha \leq 0.05)$ between the pre and post measurement for the general psychological adjustment scale and each of its dimensions for the empirical group.

In order to test this hypothesis, the averages and standard deviations were calculated for the scores of the members of the empirical group in the pre and post measurements for the total psychological adjustment scale and for each of its dimensions. The results are shown in table 7.

\begin{tabular}{|c|c|c|c|c|}
\hline Dimensions & Test & $\mathrm{N}$ & Mean & Standard Deviation \\
\hline \multirow{2}{*}{ Personal Adjustment } & Pre & 15 & 5.40 & 1.121 \\
\cline { 2 - 5 } & Post & 15 & 7.73 & 1.099 \\
\hline \multirow{2}{*}{ Social Adjustment } & Pre & 15 & 7.00 & 1.069 \\
\cline { 2 - 5 } & Post & 15 & 8.67 & 2.093 \\
\hline \multirow{2}{*}{ Familial Adjustment } & Pre & 15 & 6.33 & 2.257 \\
\cline { 2 - 5 } & Post & 15 & 8.33 & 976. \\
\hline \multirow{2}{*}{ Emotional Adjustment } & Pre & 15 & 5.53 & 2.199 \\
\cline { 2 - 5 } & Post & 15 & 10.00 & 2.752 \\
\hline \multirow{2}{*}{ Total Degree } & Pre & 15 & 24.27 & 4.383 \\
\cline { 2 - 5 } & Post & 15 & 34.73 & 5.378 \\
\hline
\end{tabular}

Table 7: The averages and standard deviations of the pre and post measurments of the total scale and each of its dimensions for the members of the empirical group.

It is clear from table 7 that the averages in the post measurement for the members of the empirical group are greater than the averages in the pre measurement in the total scale and each of its dimensions.

Given the small size of the sample, the data distribution was tested. It was found that the distribution is non-moderate. Therefore, the indications of these differences were verified by using the Wilcoxon $\mathrm{U}$ Test. Table 8 shows the results of the test. 
Citation: Al Lawati MAM (2017) Effectiveness of a Group Counseling Program in Transcendental Meditation in Improving the Level of General Psychological Adjustment for Grade Eleven Female Students in Muscat Governorate. Int J Psychol Behav Anal 2: 135. doi: https://doi.org/10.15344/2017/2455-3867/135

Page 5 of 6

\begin{tabular}{|c|c|c|c|c|c|}
\hline Dimensions & Test & $\mathrm{N}$ & Total of classes & $\mathrm{Z}$ & $\mathrm{P}$ \\
\hline Personal Adjustment & Pre & 15 & 00. & 3.324 & 001. \\
\cline { 2 - 6 } & Post & 15 & 105.00 & & \\
\hline Social Adjustment & Pre & 15 & 16.00 & 2.326 & 020. \\
\cline { 2 - 6 } & Post & 15 & 89.00 & & \\
\hline Familial Adjustment & Pre & 15 & 12.00 & 2.553 & 011. \\
\cline { 2 - 6 } & Post & 15 & 93.00 & & \\
\hline Emotional Adjustment & Pre & 15 & 3.50 & 3.087 & 002. \\
\cline { 2 - 6 } & Post & 15 & 101.50 & & \\
\hline Total Degree & Pre & 15 & 0.00 & 3.413 & 001. \\
\hline & Post & 15 & 120.00 & & \\
\hline
\end{tabular}

Table 8: Results of the Wilcoxon test for pre and postmeasurments of the total scale and each of its dimensions for the members of the empirical group.

Table 8 shows statistically significant differences at the level of significance $(\alpha \leq 0.05)$ between the pre and post measurements for the total psychological adjustment scale and for each of its dimensions. These differences were in favour of the post application at which all the statistical significances were less than (0.05). This confirms the effectiveness of the program used in the current study.

The researcher attributes this result to the fact that the TM technique is an easy rather than complex technique. It does not require much effort; it is easy to learn and it can be easily trained and practiced. Moreover, it does not require any concentration or mind control. This technique is also considered to be a natural one that has not been manipulated, and it does not require any complex physical excercise. It also suits all age groups and in particular the group targeted by the current study. The exercise of the TM technique implemented in the counseling program sessions enabled the female students tomaintain a level of personal, social, emotional and familial balance. Thus, this counseling program improved their adjustment level.

\section{Discussing the findings related to the third hypothesis}

The third hypothesis suggested that there were no statistically significant differences at the level of significance $(\alpha \leq 0.05)$ between the post and follow-up measurement on the general psychological adjustment scale for the members of the empirical group on the total scale on each of its dimensions.

In order to test this hypothesis, the averages and standard deviations were calculated for the scores of the members of the empirical group in the post and follow-upmeasurements for the psychological adjustment on the total scale and on each of its dimensions. The results are shown in table 9.

Table 9 shows apparent differences in the averages of the scores of the members of the empirical group in the post measurement and the follow-up measurement.

Given the small size of the sample, the data distribution was tested. It was found that the distribution is non-moderate. Therefore, the indications of these differences were verified by using the Wilcoxon $U$ Test. Table 10 shows the results of the test.

It is clear from table 10 that there are no statistically significant differences at the level of significance $(\alpha \leq 0.05)$ between the post
Int J Psychol Behav Anal

ISSN: 2456-3501

\begin{tabular}{|c|c|c|c|c|}
\hline Dimensions & Test & $\mathrm{N}$ & Mean & $\begin{array}{c}\text { Standard } \\
\text { Deviation }\end{array}$ \\
\hline Personal Adjustment & Post & 15 & 7.73 & 1.100 \\
\cline { 2 - 5 } & Follow-up & 15 & 7.87 & 1.187 \\
\hline \multirow{2}{*}{ Social Adjustment } & Post & 15 & 8.67 & 2.093 \\
\cline { 2 - 5 } & Follow-up & 15 & 9.27 & 2.052 \\
\hline Familial Adjustment & Post & 15 & 8.33 & 976. \\
\cline { 2 - 5 } & Follow-up & 15 & 8.53 & 1.885 \\
\hline Emotional Adjustment & Post & 15 & 10.00 & 2.752 \\
\cline { 2 - 5 } & Follow-up & 15 & 10.60 & 2.445 \\
\hline \multirow{2}{*}{ Total Degree } & Post & 15 & 34.73 & 5.378 \\
\cline { 2 - 5 } & Follow-up & 15 & 36.27 & 6.273 \\
\hline
\end{tabular}

Table 9: Averages and standard deviations of the post and follow-up measurments for the total scale and for each of its dimensions for the members of the empirical group.

\begin{tabular}{|c|c|c|c|c|c|}
\hline Dimensions & Test & $\mathrm{N}$ & $\begin{array}{c}\text { Total of } \\
\text { classes }\end{array}$ & $\mathrm{Z}$ & $\mathrm{P}$ \\
\hline Personal Adjustment & Post & 15 & 35.50 & 0.281 & 0.779 \\
\cline { 2 - 6 } & Follow-up & 15 & 42.50 & & \\
\hline Social Adjustment & Post & 15 & 22.00 & 1.357 & 0.175 \\
\cline { 2 - 6 } & Follow-up & 15 & 56.00 & & \\
\hline Familial Adjustment & Post & 15 & 25.50 & 1.095 & 0.273 \\
\cline { 2 - 6 } & Follow-up & 15 & 52.50 & & \\
\hline Emotional Adjustment & Post & 15 & 41.00 & 0.317 & 0.751 \\
\cline { 2 - 6 } & Follow-up & 15 & 50.00 & & \\
\hline Total Degree & Post & 15 & 30.00 & 1.086 & 0.277 \\
\cline { 2 - 6 } & Follow-up & 15 & 61.00 & & \\
\hline
\end{tabular}

Table 10: The results of the Wilcoxon Test for the post and follow-up measurements on the total scale and on each of its dimensions for the members of the empirical group.

measurement and the follow-up measurement for psychological adjustment on the total scale and on each of its dimensions. The statistical significance was more than (0.05). This means that the effectiveness of the counseling program used in the current study remains.

The researcher attributes the effect of the program to its comprehensiveness and the non-reliance in training on the theoretical, but on practical applications. Practicing TM was the main factor of the results observed in female students. Giving the opportunity to female students to practice some TMexercises in a natural environment has largely contributed to the sustainability of the effect of the training. In addition, the theory of CBT, on which the program is based, gave ample opportunity for the use of various counseling methods that take into consideration individual differences between the female students on the one hand, and work on modifying their thoughts and behavior on the other hand. These methods included imitation, modeling, training on relaxation and exposure, scheduling the activity, gradual tasks, assertive training, training on speaking and listening, selfawarding, deep breathing, challenging all general facts, correcting incorrect attribution, the use of imagination and self control. The counseling relationship, positive interaction and trust between the female advisor and female students played an important role in the 
Citation: Al Lawati MAM (2017) Effectiveness of a Group Counseling Program in Transcendental Meditation in Improving the Level of General Psychological Adjustment for Grade Eleven Female Students in Muscat Governorate. Int J Psychol Behav Anal 2: 135. doi: https://doi.org/10.15344/2017/2455-3867/135

Page 5 of 6

continuity of the effect of the counseling program. The number of the sessions of the program and the time of implementation has also had very clear positive effects. The longer the time to practice TM, the better the results. These reasons all contribute to the continuous effect of the program.

\section{Recommendations}

The present study indicates an improvement in the level of general psychological adjustment among the eleventh grade female students after applying a group counseling program in TM. It also shows that the effect of the follow-up remains. In the light of these positive findings, the researcher recommends the following:

1. To direct psychology specialists in schools to take advantage of the benefit of the group counseling program in TM used in this study,to help students overcome tension and psychological stress and achieve psychological health and adjustment.

2. To develop the fields of counseling and psychological services provided to students in all education institutions and to give the opportunity for students to practice TM in class rooms every day before the school day starts.

3. To take advantage of TM techniques and use them with students as alternative preventive and therapeutic services.

4. To build counseling programs in TM based on various psychological counseling theories and to maximize their effectiveness in improving psychological adjustment among students.

5. To implement suitable counseling programs in TM to improve students' abilities in other fields, such as enhancing their academic performance and addressing learning and motivation difficulties.

6. To enrich the libraries in higher education institutions by providing them with specialised studies in the field of TM in order to facilitate further scientific research.

\section{Competing Interests}

The authors declare that they have no competing interests.

\section{References}

1. Al-Buraidi AA (2010) The Effectivness of Group Councelling Program in Decreasing the Psychological Stress among Post Primary Education Students (Unpublished MA thesis). Nizwa University: Sultanate of Oman.

2. Boeving NG (2014) Transcendental Meditation. P: 1814, Encyclopedia of Psychology and Religion. Boston, MA: Springer US.

3. Mirhij RIM (2001) Our Children from Birth to Adolescence. Beirut: Academia International for Publishing and Printing.

4. Ministry of Education (2007) The appendix attached to the ministerial decision No. (160/2007). Muscat: Author.

5. Shecter HW (1977) A Psychological Investigation into the Source of the Effect of the Transcendental Meditation Technique (Unpublished Ph.D. Dissertation). York University.

6. Ahlstrom HHB (1991) Transcendental Meditation, Adaptation Mechanisms and Valuations. ProQuest, UMI Dissertations Publishing.

7. Bodian S (2012) Meditation for Dummies. New York: John Wiley \& Sons Inc.

8. Frew DR (1974) Transcendental Meditation and Productivity. The Academy of Management Journal 17: 362-368.

9. Hanley CP, Spates JL (1978) Transcendental Meditation and Social Psychological Attitudes. Journal of Psychology 99: 121-127.
10. Chandler HM, Alexander CN, Heaton DP (2005) The transcendental meditation program and post conventional self-development: A 10-year longitudinal study. Journal of Social Behavior and Personality 17: 93- 121.

11. Grosswald SJ, Stixrud WR, Travis F, Bateh MA (2008) Use of the Transcendental Meditation Technique to Reduce Symptoms of Attention Deficit Hyperactivity Disorder (ADHD) by Reducing Stress and Anxiety: An Exploratory Study. Current Issues in Education 10: 1-12.

12. Tanner MA (2008) The Effect of Transcendental Meditation on Mindfulness. ProQuest, UMI Dissertations Publishing.

13. Elder C, Nidich S, Colbert R, Hagelin J, Grayshield L, Oviedo-Lim D Gerace D (2011) Reduced Psychological Distress in Racial and Ethnic Minority Students Practicing the Transcendental Meditation Program. Journal of Instructional Psychology 38: 109-117.

14. Nidich S, Mjasiri S, Nidich R, Rainforth M, Grant J, et al. (2011) Academic Achievement and Transcendental Meditation: A study with at-risk urban middle school students. Mobile: Project Innovation, Inc.

15. Aldahadha B (2013) The effects of Muslim praying meditation and transcendental meditation programs on mindfulness among the University of Nizwa students. College Student Journal 47: 668-676.

16. Napora L (2013) The Impact of Classroom-Based Meditation Practice on Cognitive Engagement, Mindfulness and Academic Performance of Undergraduate College Students (Doctoral dissertation). State University of New York at Buffalo.

17. Ramsburg JT, Youmans RJ (2014) Meditation in the Higher-Education Classroom: Meditation Training Improves Student Knowledge Retention during Lectures. Mindfulness 5: 431-441.

18. Dwairy M (2009) Parenting and Adolescent's Psychological Adjustment: Toward a Systemic Approach in Parenting Research. The Open Family Studies Journal 2: 66-74.

19. Al-Atawi MA(2013)The Effectivness of Knowledge BehaviouralCouncelling Program to Enhance the Level of Psychological Social Adjustment and Decreasing the Desire to Drop Out from School among Secondary School Students at Tabook region (Ph.D. dissertation). Teeba University: Saudi Arabia.

20. Turnbull M, Norris H (1982) Effects of Transcendental Meditation on SelfIdentity Indexes and Personality. British Journal of Psychology 73: 57-68.

21. Hong Z, Lin H, Wang H, Chen H, Yu T (2012) The Effects of Functional Group Counseling on Inspiring Low-Achieving Students' Self-Worth and Self-Efficacy in Taiwan. International Journal of Psychology 47: 179-191.

22. Sirri IM (1986) The General Ssychological Adjustment Scale. Educational Studies 2: 162-163. 